\title{
La capital de los Estados \\ Unidos Mexicanos: Una ciudad constitucionalmente adjetivada
}

The capital of the United Mexican States: A constitutionally adjective city

A capital dos Estados Unidos Mexicanos: uma cidade constitucionalmente adjetiva

La capitale des États-Unis du Mexique: une ville constitutionnellement adjectivale

墨西哥合众国的首都: 宪法规定的形容词城市

\author{
Alejandra Boto Álvarez ${ }^{1}$ \\ Universidad de Oviedo, España
}

Revista Derechos en Acción ISSN 2525-1678/ e-ISSN 2525-1686

Año 6/Nº 19 0toño 2021 (21 marzo a 20 junio), 184-208

DOI: https://doi.org/10.24215/25251678e514

Recibido: 04/03/2021

Aprobado: 15/05/2021

Resumen: El trabajo se centra en la Constitución política de la Ciudad de México, aprobada en 2017 y que, en el marco de una tendencia global, da un gran protagonismo al fenómeno urbano. Siguiendo el método de análisis jurídico, se describe el contexto en que surge este primer texto constitucional para la capital federal de los Estados Unidos Mexicanos, y se presta atención especial a su forma y a su fondo. Se destaca en

\footnotetext{
1 Autora de cuatro monografías científicas y de más de una treintena de artículos publicados en revistas jurídicas del máximo impacto en España, Francia, Italia, Eslovenia, Colombia, Argentina, Canadá y los Estados Unidos. Sus campos de especialización son la organización administrativa y el Derecho público comparado, así como las cuestiones ligadas al ámbito sanitario y el Estado del bienestar. botoalejandra@uniovi.es (ORCID https://orcid.org/00000002-7616-1236).
} 
particular el carácter nuclear de la ciudad, que se adjetiva con una profusión muy llamativa. El análisis se cierra con una reflexión crítica sobre el auténtico valor de la norma y de esta adjetivación, desde la perspectiva del contenido normativo aplicable y sus garantías, pero también como símbolo cultural e imagen de consenso.

Palabras clave: ciudad; derechos; constitución; normatividad.

Abstract: This paper focuses on the Political Constitution of Mexico City, adopted in 2017 and which, within the framework of a global trend, gives a great prominence to the urban phenomenon. Following the method of legal analysis, it describes the context in which this first constitutional text for the federal capital of the United Mexican States has emerged, and special attention is paid to its form and substance. The city is a nuclear character of the Constitution, with plenty of adjectives added in an extremely striking way. The analysis concludes with a critical reflection on the real value of the piece of law itself and of the adjectives for the city, from the perspective of the applicable normative content and its guarantees, but also as a cultural symbol and image of consensus.

Keywords: city; rights; constitution; normativity.

Resumo: 0 trabalho enfoca a Constituição Política da Cidade do México, aprovada em 2017 e que, no marco de uma tendência mundial, dá grande destaque ao fenômeno urbano. Seguindo o método da análise jurídica, descreve-se o contexto em que surgiu este primeiro texto constitucional para a capital federal dos Estados Unidos Mexicanos, com atenção especial à sua forma e conteúdo. 0 caráter nuclear da cidade se destaca em particular, que é um adjetivo com uma profusão muito marcante. A análise termina com uma reflexão crítica sobre o verdadeiro valor da norma e deste adjectivo, do ponto de vista do conteúdo normativo aplicável e das suas garantias, mas também como símbolo cultural e imagem de consenso.

Palavras-chave: Cidade, Direitos, Constituição, normatividade.

Résumé: Les travaux portent sur la Constitution politique de Mexico, approuvée en 2017 et qui, dans le cadre d'une tendance mondiale, donne une grande importance au phénomène urbain. Suivant la méthode de I'analyse juridique, le contexte dans lequel ce premier texte constitutionnel est né pour la capitale fédérale des États-Unis mexicains est décrit et une attention particulière est portée à sa forme et à sa substance. 
Le caractère nucléaire de la ville se distingue en particulier, qui est un adjectif avec une profusion très frappante. L'analyse se termine par une réflexion critique sur la vraie valeur de la norme et de cet adjectif, du point de vue du contenu normatif applicable et de ses garanties, mais aussi comme symbole culturel et image du consensus.

Mot-clés: Ville, droits, Constitution, normativité.

摘要: 该工作的重点是2017年批准的墨西哥城政治宪法在全球趋势 的框架内该现象极大地突出了城市现象. 按照法律分析的方法描述 了墨西哥合众国联邦首都第一部宪法文本出现的背景并特别关注 其形式和实质这座城市的核特征尤其引人注目令人印象深刻令人 叹为观止. 从适用的规范内容及其保证的角度也作为一种文化的符 号和共识的形象分析结束时对规范和该形容词的真实价值进行了 批判性的反思.

关键字: 镇, 权利, 宪法, 规范性

\section{Introducción}

El fenómeno urbano es un auténtico trending topic académico. No es de extrañar, dado que hoy en día más de la mitad de la humanidad vive en las ciudades, y la tendencia seguirá al alza a medio plazo según todas las previsiones oficiales. De entre las diversas ramas de conocimiento, el Derecho público se viene encargando también de este fenómeno cada vez con mayor intensidad. Esto tampoco resulta sorprendente, puesto que al fin y al cabo todo lo que tiene que ver con el urbanismo en sentido amplio nace en origen muy vinculado al Derecho Administrativo, con una columna vertebral clásica en el poder de policía para ornato y salubridad en las ciudades, que después evolucionaría de la mano del concepto de plan, hasta la moderna ordenación del territorio (Martín Rebollo, 2009, págs. 66-68) ${ }^{2}$. Así, el XV Congreso de la Asociación Española de

2 MARTín REBOLLO, Luis (2009). "Derecho urbanístico: concepto y contenido", en MARTIN REBOLLO, Luis y BUSTILLO BOLADO, Roberto 0. (dir.), Fundamentos de Derecho Urbanístico, tomo I, págs. 65-79. Cizur Menor: Aranzadi-Thomson Reuters, Madrid. 
Profesores de Derecho Administrativo, celebrado en febrero de 2020 en Ibiza, se centró en el análisis de las transformaciones y retos de ciudad del siglo XXI, subrayando precisamente la indiscutible relevancia administrativista de la ciudad.

De entre las enriquecedoras ponencias y comunicaciones presentadas en ese Congreso, procede ahora destacar la firmada por la profesora de la Sierra que, a partir de la constatación de que la ciudad ya no es sólo un punto de llegada sino también de partida, analiza los diversos efectos de un fenómeno pujante: el de unas adjetivaciones que la mayor parte de las veces se vinculan a cuestiones de marketing y de "Marca Ciudad", pero en otros comportan auténticas consecuencias jurídicas (de la Sierra Morón, 2020) ${ }^{3}$.

Siguiendo esa estela, este trabajo tiene como sustrato de estudio el ámbito de la Ciudad por excelencia: Ciudad de México, cuya primera Constitución, aprobada en 2017, precisamente la concibe de forma adjetivada hasta el extremo.

Ciudad de México, la aglomeración urbana más grande del continente americano y del orbe hispanohablante, es vista por el preámbulo de su Constitución, tópicamente la parte más dada al lenguaje "poético" de las normas (Gómez Sánchez, 1991)", como una ciudad intercultural y hospitalaria, civilizatoria, libre, laica, digna y transparente. Pero, además y lo que es más llamativo, ya en la parte dispositiva del texto, la Ciudad se concibe como intercultural, pluriétnica, plurilingüe y pluricultural (art. 2), garantista (art. 5), de libertades y derechos (art. 6), democrática (art. 7), educadora y del conocimiento (art. 8), solidaria (art. 9), productiva (art. 10), incluyente (art. 11), habitable (art. 13), segura

3 DE LA SIERRA MORON, Susana (2020). "Las ciudades adjetivadas", Revista general de Derecho Administrativo, núm. 55. Disponible en: https://dialnet.unirioja.es/servlet/articulo? codigo $=7640356$

4 GÓMEZ SANCHEZ, Juan Pablo (1991). “De los preámbulos y liminares constitucionales como metatextos (en el texto constitucional hispanoamericano)", en ELUA. Estudios de Lingüística, núm. 7, págs. 117-136. Fecha de consulta: 14-09-2020. DOI: http://dx.doi. org/10.14198/ELUA1991.7.06. 
(art. 14) y global (art. 20). Todos estos adjetivos constituyen los intitulados de los respectivos artículos. La ciudad pluricultural es además el tenor de todo un capítulo (el VII, art. 57-59). Sólo por ello entiendo que el caso puede merecer un análisis detallado, pero además la Ciudad de México es un buen ejemplo del concepto renovado de ciudad, un conglomerado urbano no encorsetado por perímetros municipales, pues hablamos -como se verá- de un nivel de gobierno y administración superior a estos, y necesitado de soluciones metropolitanas (Tolivar Alas, 2020).

Tras una breve presentación de la génesis de la Constitución política de la Ciudad de México que, redactada desde una perspectiva de derechos, entre otras cosas contiene una regulación positiva concreta del derecho $a$ la ciudad y de distintos derechos en la ciudad (Alonso Ibáñez, 2018) ${ }^{6}$, se presta atención especial al contenido efectivo de la profusa adjetivación constitucionalizada de la megalópolis. Esta, quizá, ante todo, sigue siendo la capital de los Estados Unidos Mexicanos.

\section{La construcción de la Ciudad de México a partir de la capitalidad federal}

Formalmente, la Ciudad de México nace como tal en 2016, al culminarse el proceso de la llamada Reforma Política del Distrito Federal (Concha Cantú, 2017) ${ }^{7}$. Ello daría lugar a la reforma de la Constitución federal primero y la apertura posterior del primer proceso constituyente en su capital. El poder constituyente se integró por 100 diputados, 40 de ellos designados por órganos

5 TOLIVAR, Alas (2020). "Gobierno dé y desde la ciudad", en BARRERO RODRÍGUEZ, C. y SOCÍAS CAMACHO, J. M. (coord.), La ciudad del siglo XXI: transformaciones y retos, págs. 59-83. INAP, Madrid.

6 ALONSO IBAÑEZ, Marcelo dir. (2018). La sostenibilidad socioeconómica de las ciudades. Estudios jurídicos. Tirant lo Blanch, Valencia.

7 CONCHA CANTÚ, Hugo Alejandro (2017). “La evolución político-institucional de la Ciudad de México", en Esquivel, G., Ibarra Palafox, F. A. y Salazar Ugarte, P. (coord.), Cien ensayos para el centenario. Constitución Política de los Estados Unidos Mexicanos, págs. 53-74, tomo 4: Estudios políticos. UNAM-Instituto de Investigaciones Jurídicas-Instituto Belisario Domínguez, México. 
políticos ya constituidos (Presidente de la República, Cámaras de Diputados y Senadores y Jefe de Gobierno del Distrito Federal) y 60 electos mediante voto público. Hubo además un Grupo Redactor, multidisciplinar, integrado por 30 personalidades de la academia, de la sociedad civil organizada, de la Administración pública, así como de la vida política nacional y de la ciudad. La Constitución política de la Ciudad de México vería finalmente la luz en 2017; sobre la utilidad y necesidad de este texto puede verse Serna de la Garza $(2016)^{8}$. En general sobre la convivencia de distintos textos constitucionales en México: Martí Capitanachi (2002)9.

A su vez, la creación del Distrito Federal se había concretado en una Ley constitucional expedida por el Congreso Constituyente el 18 de noviembre de 1824. Anteriormente, la Ciudad de México era capital del Estado de México. Para justificar el cambio al Distrito Federal se esgrimió en su momento el argumento de la imposibilidad de que existieran dos jurisdicciones en un mismo territorio. La interpretación de la relación entre el Distrito Federal y la Federación ha partido siempre de la no confusión pues, aunque formalmente mantuviera una relación de dependencia con la Federación, desde el punto de vista material el Distrito Federal era una entidad local diferente a la misma (Mejía Garza, 2017) ${ }^{10}$.

El Distrito Federal en todo momento fue en efecto una entidad sui generis (López Olvera, 2005) ${ }^{11}$, detrás de la que latían

8 SERNA DE LA GARZA, José María (2016). "Reflexiones sobre la justificación de una Constitución para la Ciudad de México", en VV.AA., Hacia una Constitución para la Ciudad de México, págs. 51-59. México: Senado de la República.

9 MARTÍ CAPITANICH, Lucas (2002). "Las Constituciones locales en el sistema federal mexicano ¿son verdaderas constituciones?", en SERNA DE LA GARZA, J. M. (coord.), Federalismo y regionalismo, pp. 645-661. México: UNAM-Instituto de Investigaciones Jurídicas.

10 MEJía gARZA, Raúl Manuel (2017). "Artículo 43" y "Artículo 44", en cossío, J. R. (coord.), Constitución política de los Estados Unidos Mexicanos comentada, págs. 869 y ss. Ciudad de México: Tirant lo Blanch.

11 LÓPEZ OLVERA, Jorge (2005). “Marco constitucional de la Administración pública del Distrito Federal", en Fernández Ruíz, J. (coord.), La Constitución y el Derecho Administrativo, 
tensiones distintas y aspiraciones de una autonomía creciente (González Oropeza, 2002) ${ }^{12}$. La situación llegó a tornarse insostenible debido a distintos factores demográficos, sociales y también económicos (Ibarra Muñoz y Dosal, 2016, págs. 3-40) ${ }^{13}$. Las principales críticas tenían que ver con la débil representación política de sus habitantes (Matute González, 2018, pág. 237) ${ }^{14}$.

La evolución y los hitos más característicos de la referida Reforma Política, así como los antecedentes de la misma, se reflejan en la Figura 1.

Fig. 1: Del Distrito Federal (DF) a la Ciudad de México (CDMX)

\begin{tabular}{|l|l|l|}
\hline \multicolumn{1}{|c|}{ Fecha } & \multicolumn{1}{|c|}{ Hito } & \multicolumn{1}{c|}{ Principales características } \\
\hline $1325-1521$ & $\begin{array}{l}\text { Tenochtitlán-capital de } \\
\text { Nueva España }\end{array}$ & Precedentes históricos del DF \\
\hline 1824 & $\begin{array}{l}\text { Primera Constitución } \\
\text { mexicana }\end{array}$ & $\begin{array}{l}\text { Establecimiento del DF. Residencia de } \\
\text { los supremos poderes de la Federación. } \\
\text { Formalmente no se considera una entidad } \\
\text { federativa. }\end{array}$ \\
\hline 1836 & Etapa centralista & $\begin{array}{l}\text { Sustitución del DF por el Departamento de } \\
\text { México. Ciudad de México sigue siendo } \\
\text { capital del país. }\end{array}$ \\
\hline $1846-1847$ & $\begin{array}{l}\text { Restablecimiento } \\
\text { Constitución 1824 }\end{array}$ & $\begin{array}{l}\text { Restablecimiento del DF. Gobierno } \\
\text { encomendado a poderes federales. } \\
\text { Consideración implícita como entidad } \\
\text { federativa. }\end{array}$ \\
\hline
\end{tabular}

págs. 165-185. México: UNAM-Instituto de Investigaciones Jurídicas-Consejo Nacional de Ciencia y Tecnología.

12 GONZALEZ OROPEZA, Manuel (2002). "La condición jurídica de la sede de los poderes federales en México", en SERNA DE LA GARZA, J. M. (coord.), Federalismo y regionalismo, págs. 183-196. México: UNAM-Instituto de Investigaciones Jurídicas.

13 IBARRA MUÑOZ, David. y DOSAL, Ricardo. (2016). "La ciudad de México y su nueva constitución en el entorno nacional", en Economía UNAM, núm. 38, págs. 3-40. Fecha consulta 14-09-2020. URL: http://www.revistas.unam.mx/index.php/ecu/article/view/55357

14 MATUTE GONZALEZ, Fernando (2018). El Estado de las autonomías y el buen gobierno. Tirant lo Blanch, Ciudad de México. 


\begin{tabular}{|c|c|c|}
\hline Fecha & Hito & Principales características \\
\hline 1857 & $\begin{array}{l}\text { Constitución federal } \\
\text { de los Estados Unidos } \\
\text { Mexicanos }\end{array}$ & $\begin{array}{l}\text { Mantenimiento del DF. Primeras aspi- } \\
\text { raciones de independizar a la ciudad de } \\
\text { México de la tutela federal, elevándola a } \\
\text { la categoría de Estado (frustradas). }\end{array}$ \\
\hline 1859 & Régimen Habsburgo & Capital del Imperio. \\
\hline $1867-1874$ & $\begin{array}{l}\text { Restablecimiento } \\
\text { constitucional }\end{array}$ & Restablecimiento DF. \\
\hline 1901 & Régimen de Porfirio Díaz & $\begin{array}{l}\text { Se atribuye al Congreso de la Unión } \\
\text { competencia para legislar en los asuntos } \\
\text { relativos al DF }\end{array}$ \\
\hline 1903 & $\begin{array}{l}\text { Ley de Organización Po- } \\
\text { lítica y Municipal del DF }\end{array}$ & $\begin{array}{l}\text { Gobierno y Administración corresponden a } \\
\text { órganos federales. }\end{array}$ \\
\hline 1917 & $\begin{array}{l}\text { Constitución política } \\
\text { de los Estados Unidos } \\
\text { Mexicanos (CPEUM) }\end{array}$ & $\begin{array}{l}\text { Gobierno dependiente del Presidente } \\
\text { de la República; legislación a cargo del } \\
\text { Congreso de la Unión. }\end{array}$ \\
\hline 1897 & Reforma constitucional & $\begin{array}{l}\text { Crea la Asamblea de Representantes del DF, } \\
\text { germen de un futuro poder legislativo propio. }\end{array}$ \\
\hline 1994 & Reforma constitucional & Se crea el Consejo de la Judicatura del DF. \\
\hline 1997 & Reforma constitucional & $\begin{array}{l}\text { Nace la Asamblea Legislativa del DF y } \\
\text { su Jefe de Gobierno pasa a elegirse por } \\
\text { voto directo de los ciudadanos y no por } \\
\text { designación federal. }\end{array}$ \\
\hline 2001-2009 & $\begin{array}{l}\text { Programa de Reforma } \\
\text { política del DF }\end{array}$ & $\begin{array}{l}\text { Se aspira a conseguir más autonomía sin que } \\
\text { eso tenga que suponer dejar de ser la sede } \\
\text { de los poderes federales o la capital del país }\end{array}$ \\
\hline 2016 & Reforma constitucional & DF desaparece de CPEUM. Nace CDMX. \\
\hline 2017 & $\begin{array}{l}\text { Constitución política de } \\
\text { CDMX }\end{array}$ & $\begin{array}{l}\text { Deroga a la vieja institución del Estatuto } \\
\text { de Gobierno del DF. Primera constitución } \\
\text { local no estatal. }\end{array}$ \\
\hline
\end{tabular}

Fuente: Elaboración propia a partir de Camacho Vargas (2016) ${ }^{15}$ y Olvera Acevedo (2019) ${ }^{16}$.

15 CAMACHO VARVAS, Jorge (2016). "Evolución constitucional de la Ciudad de México", en V.AA., Apuntes y comentarios a la esencia constitucional mexicana (1917-2016), págs. 416-435. Ciudad de México: Publicaciones de la Cámara de Diputados.

16 OLVERA ACEVEDO, Alejandro (2019). Ciudad de México. La reforma jurídico-política del Distrito Federal. Tirant lo Blanch, Ciudad de México. 
En su redacción vigente, y fruto de la reforma de 2016 (operada por Decreto de la Comisión Permanente del Honorable Congreso de la Unión firmado por el Presidente el 29 de enero de 2016), la Constitución federal dispone en su artículo 40 que

es voluntad del pueblo mexicano constituirse en una República representativa, democrática, laica y federal, compuesta por Estados libres y soberanos en todo lo concerniente a su régimen interior, y por la Ciudad de México, unidos en una federación establecida según los principios de esta ley fundamental.

Las partes integrantes de la Federación son 31 Estados $^{17}$; así como la Ciudad de México (art. 43). La Ciudad de México es la entidad federativa sede de los Poderes de la Unión y Capital de los Estados Unidos Mexicanos; se compondrá del territorio que actualmente tiene y expresamente se prevé que, en caso de que los poderes federales se trasladen a otro lugar, se erigirá en un Estado de la Unión con la denominación de Ciudad de México (art. 44).

Por su parte, la Constitución política de la Ciudad de México, publicada en la Gaceta Oficial de la Ciudad de México de 5 de febrero de 2017, dispone que esta es la capital de los Estados Unidos Mexicanos, sede de sus poderes y entidad integrante de la Federación (art. 1). Adopta una forma de gobierno republicana, democrática, representativa, laica y popular, bajo un sistema de división de poderes, pluralismo político y participación social (art. 1.3 y 28). Territorialmente, la Ciudad se articula en 16 demarcaciones ${ }^{18}$, autónomas en su gobierno interior, a cargo

17 Aguascalientes, Baja California, Baja California Sur, Campeche, Coahuila de Zaragoza, Colima, Chiapas, Chihuahua, Durango, Guanajuato, Guerrero, Hidalgo, Jalisco, México, Michoacán, Morelos, Nayarit, Nuevo León, Oaxaca, Puebla, Querétaro, Quintana Roo, San Luis Potosí, Sinaloa, Sonora, Tabasco, Tamaulipas, Tlaxcala, Veracruz, Yucatán y Zacatecas.

18 Álvaro Obregón, Azcapotzalco, Benito Juárez, Coyoacán, Cuajimalpa de Morelos, Cuauhtémoc, Gustavo A. Madero, Iztacalco, Iztapalapa, La Magdalena Contreras, Miguel Hidalgo, Milpa Alta, Tláhuac, Tlalpan, Venustiano Carranza y Xochimilco. El perímetro y denominación de estas demarcaciones coincide con las delegaciones políticas preexistentes, 
de una Alcaldía dotada de personalidad jurídica y autonomía con respecto a su administración. El gobierno local y la autonomía se han visto así reforzados con la reforma ${ }^{19}$ (Quintana Balbín, 2017) ${ }^{20}$, si bien aún quedan bastantes retos pendientes sobre todo en relación con el fenómeno metropolitano y la participación ciudadana.

\section{La ciudad y los derechos en la Constitución de la Ciudad de México}

La Constitución de la Ciudad de México de 2017 es un texto sumamente interesante desde muchas perspectivas. Así, frente a la Constitución federal y a las estatales, contiene novedades como el reconocimiento de nuevos derechos humanos ${ }^{21}$, la ampliación de los derechos de los pueblos originarios y comunidades indígenas residentes, y mecanismos de democracia

\footnotetext{
de conformidad con el artículo 6 de la Ley Orgánica de Alcaldías de la Ciudad de México, publicada en la Gaceta Oficial de la Ciudad de México el 4 de mayo de 2018.

19 Es más, la Ley Orgánica citada en la nota precedente incluso reconoce personalidad jurídica a los pueblos y barrios originarios y a las comunidades indígenas residentes establecidos en sus demarcaciones territoriales, y, con ello, a sus autoridades y representantes legal y legítimamente nombrados en el marco de sus sistemas normativos, como sujetos colectivos de derecho (art. 215).
}

20 QUINTANA, Balbín (2017). "La Ciudad de México y la vida municipal", en RENDÓN HUERTA BARRERA, T. (coord.), Hacer ciudad, hacer ciencia. La agenda de los gobiernos locales del siglo XXI. Homenaje a Alicia Ziccardi Contigiani, págs. 223-247. Ciudad de México: Tirant Io Blanch.

21 La cuestión fue objeto de una acción de inconstitucionalidad, por entenderse que la regulación de los derechos humanos a nivel local altera el sistema constitucional y convencional al que está sujeto el Estado mexicano. La Suprema Corte de Justicia de la Nación entendió que el Constituyente de la Ciudad de México tenía facultades para legislar sobre derechos humanos, desarrollarlos e, incluso, crear nuevos derechos, siempre y cuando se respetasen los ámbitos de competencia de la Federación, de las otras entidades federativas y el contenido de los derechos humanos que forman parte del bloque de constitucionalidad (Sentencia de 6 de septiembre de 2018, dictada en la acción de inconstitucionalidad 15/2017 y sus acumuladas 16/2017, 18/2017 y 19/2017, publicada en el Diario Oficial de la Federación de 25 de abril de 2019). La sentencia tiene casi 400 páginas, con votos particulares de 9 de los 11 magistrados del pleno, lo que en cierta manera puede explicar el gran retraso, no ya en su adopción, sino sobre todo en su publicación posterior. 
directa y participativa. Sin embargo, también es un texto criticado por presentar una cierta impronta neoliberal, por no haber recogido derechos como la renta básica, la ciudadanía universal o la desobediencia civil (Cárdenas Gracia, 2017, pág. 104) 22. Asimismo, se ha tildado de "error histórico" el no haber previsto un régimen de competencias único y ajustado a su propia realidad (Rabell García, 2017, pág. 268) ${ }^{23}$. Tal y como explica Orozco $(2017)^{24}$, se llegaron a impugnar 40 de los 71 artículos de la Constitución de la Ciudad a través de un amparo y siete recursos: cuatro acciones de inconstitucionalidad y tres controversias constitucionales.

Estamos ante un texto que integra 71 artículos estructurados en ocho títulos. En el primero existen tres disposiciones generales; el segundo consagra una "Carta de Derechos" y se compone de dos capítulos: el primero se dedica a las normas y garantías de los derechos humanos y el segundo, propiamente a estos derechos. El título tercero, con un capítulo único, versa sobre el desarrollo y planeación democrática. El cuarto título, bajo el lema de ciudadanía y ejercicio democrático contiene de nuevo dos capítulos, el primero sobre las personas originarias y las que habitan la Ciudad de México, y el segundo sobre democracia directa, participativa y representativa. En el título quinto (consagrado a la distribución de poder) existe un artículo inicial que no se engloba en un capítulo propio, y que se refiere al poder público de la Ciudad; después se abren siete capítulos. De forma bastante sistemática, el primero se dedica a la función legislativa, el segundo a la función ejecutiva y el tercero a la función judicial. A partir de ahí,

\footnotetext{
22 CÀrdenAS GRACIA, Jaime (2017). La Constitución de la Ciudad de México. Análisis crítico. UNAM-Instituto de Investigaciones Jurídicas, México.

23 RABELL GARCÍA, Enrique (2017). "La reforma política de la Ciudad de México", en Cuestiones constitucionales, núm. 36, págs. 243-270. Fecha consulta 14-09-2020. Disponible en: https://www.redalyc.org/pdf/885/88552786009.pdf.

24 OROZCO, Jorge (2017). "Las impugnaciones a la Constitución Política de la Ciudad de México. Temas Estratégicos, núm. 46. Fecha consulta 14-09-2020. Disponible en: http:// bibliodigitalibd.senado.gob.mx/handle/123456789/3500.
} 
el capítulo cuarto se titula seguridad ciudadana y procuración de justicia; el quinto a los organismos autónomos, el sexto a las demarcaciones territoriales y Alcaldías, y el séptimo y último a la ciudad pluricultural. El título sexto se inicia también con un artículo suelto, sobre debido ejercicio y probidad en la función pública, antes de dividirse en dos capítulos, el primero sobre el combate a la corrupción y el otro sobre el régimen de responsabilidades. El séptimo título se centra en el carácter de capital de los Estados Unidos Mexicanos y tiene un único artículo sin mención de capítulo y que se refiere al régimen de capitalidad ${ }^{25}$. El octavo y último título de la parte dispositiva de la Constitución se consagra a la estabilidad constitucional y contiene tres artículos, se nuevo sin división capitular. Existen además 39 disposiciones transitorias. El texto es en su conjunto largo y farragoso; y es que, si bien el número de artículos no parece excesivo, todos tienen textos muy largos con varias subdivisiones internas y una prosa reiterativa y en gran medida tautológica. Ello complica considerablemente la lectura, el análisis y la cita de los preceptos ${ }^{26}$.

Uno de sus más loados logros es la concreción del derecho a la ciudad en su artículo 12, señalando que consiste en el uso y el usufructo pleno y equitativo de la ciudad. Se funda en los principios de justicia social, democracia, participación, igualdad, sustentabilidad, de respeto a la diversidad cultural, a la naturaleza y al medio ambiente, y se configura como

un derecho colectivo que garantiza el ejercicio pleno de los derechos humanos, la función social de la ciudad, su gestión democrática y asegura la justicia territorial, la inclusión social y la distribución equitativa de bienes públicos con la participación de la ciudadanía.

Se trata de un avance importante tratando de positivizar las ideas políticas de finales de los años sesenta de Lefebvre; sin

25 Esta vez no se indica siquiera que se trate de un capítulo único a diferencia de la opción por la que se decantó el constituyente en el título tercero ya comentado.

26 El texto de la Constitución ocupa de hecho 180 páginas del Boletín Oficial. 
embargo, el derecho a la ciudad no es sólo un catálogo de derechos, ha de complementarse con políticas públicas e instrumentos técnico- jurídicos para poder ejercerlos (Borja, 2018, pág. 15$)^{27}$. Es aquí donde la Constitución de la capital federal presenta sus mayores debilidades, tal y como se tratará de exponer.

Antes, sin ánimo exhaustivo, se comentan algunos derechos con dimensión urbana que engarzan con el derecho a la ciudad. Dada la gran extensión del texto constitucional, y las limitaciones de espacio de este trabajo, se utilizan como guía los derechos destacados por el profesor Ponce Solé (2019) ${ }^{28}$ y así cabe señalar:

\subsection{En materia de desarrollo (sostenible) local y derecho a medioambiente}

El desarrollo económico sustentable y solidario con visión metropolitana es un principio rector que la Ciudad de México asume en su artículo 3.2.a). La promoción del desarrollo sostenible es una obligación de las autoridades públicas en el marco al derecho a una vida digna (art. 9.A) para que, progresivamente, se erradiquen las desigualdades estructurales y la pobreza, y se alcance una justa distribución de la riqueza y del ingreso entre personas, familias, grupos sociales y ámbitos territoriales. Ese mismo artículo establece que todas las personas tienen derecho a un mínimo vital para asegurar una vida digna en los términos de la misma Constitución (Aguirre Hernández, 2018) ${ }^{29}$.

27 BORJA, Jordi (2018). "Ciudadanía y Derechos en una nueva era", en CORTI, Horacio y BORJA, Jordi Derecho a la ciudad: conquista política y renovación jurídica, págs. 15-96. Jusbaires, Buenos Aires.

28 PONCE SOLÉ, Julia (2019). “El derecho a la ciudad y la Nueva Agenda Urbana: una aproximación integrada y sistémica a los derechos en la ciudad con referencia al derecho a la vivienda", en PONCE SOLÉ, Julia, MIGLIARI, W. y CAPDEFERRO Villagrasa, 0. (coords.), EI derecho, la ciudad y la vivienda en la nueva concepción del desarrollo urbano, págs. 115-151. Atelier, Barcelona.

29 AGUIRRE HERNÁNDEZ, Jorge Manuel (2018). Dignidad humana y mínimo vital: dos derechos de construcción jurisprudencial contra la pobreza. Tirant lo Blanch, Ciudad de México. 
En el marco de la ciudad productiva (art. 10) se reconoce un derecho al desarrollo sustentable, según el cual toda persona tiene derecho a participar en un desarrollo económico, social, cultural y político en el que puedan realizarse plenamente todos los derechos humanos y libertades fundamentales.

Y en relación con la ciudad habitable (art. 13) se consagra el derecho a un medio ambiente sano para el desarrollo y bienestar de la persona, así como el derecho a la vía y al espacio público. El precepto deriva de una iniciativa ciudadana presentada el 25 de octubre de 2016 ante la Mesa Directiva de la Asamblea Constituyente, propuesta por más de sesenta asociaciones, actores sociales y ciudadanos que buscaban que la Constitución previera una concepción integral del entorno, alejada del antropocentrismo tradicional y entre otras cosas dispone que los espacios públicos son bienes comunes. Tienen una función política, social, educativa, cultural, lúdica y recreativa. Las personas tienen derecho a usar, disfrutar y aprovechar todos los espacios públicos para la convivencia pacífica y el ejercicio de las libertades políticas y sociales reconocidas por esta Constitución, de conformidad con lo previsto por la ley. Se entiende por espacio público el conjunto de bienes de uso común destinados a la generación y fomento de la interacción social, o bien, que permitan el desarrollo de las personas.

Pero, además, al desarrollo sustentable de la ciudad se consagra todo el Título III de la norma, donde se regulan cuestiones de ordenación del territorio y planeamiento, vivienda e infraestructuras, entre otras muchas cosas (art. 15-21). Es una muestra del carácter global de los principios de sostenibilidad urbanística que, frente al modelo expansivo tradicional, han llegado asimismo a nuestro ámbito nacional por influencia, en nuestro caso, del soft law de la Unión Europea (Quintana López, 2018, págs. 22-30) ${ }^{30}$.

30 QUINTANA LOPEZ, Tomas (2018). Cambio de paradigma: del urbanismo expansivo a la sostenibilidad. Universidad de León, León. 
Volviendo al desarrollo local en la Constitución de la Ciudad de México, también se configura como una finalidad de las Alcaldías (art. 53); la previsión en este caso trasciende además fronteras, de manera que no hay una limitación al desarrollo propio, sino la consagración de una atribución local para una auténtica cooperación al desarrollo internacional. Es una previsión avanzada, en el marco de lo que se ha identificado doctrinalmente con una "democracia cosmopolita", que lleva a la ciudad a ser un espacio de afirmación de derechos y de apoyo a la construcción de instituciones (Malaret i García, 2006, pág. 87) 31. $^{31}$.

\subsection{En relación con el derecho a la igualdad y la prohibición de discriminación}

Además de ser asimismo un principio rector de la Ciudad de México (art. 3), la igualdad y no discriminación se configura como un principio de interpretación y aplicación de los derechos humanos (art. 4). Se garantiza la igualdad sustantiva entre todas las personas sin distinción por cualquiera de las condiciones de diversidad humana. Y se dispone que las autoridades adoptarán medidas de nivelación, inclusión y acción afirmativa. En concreto, se prohíbe toda forma de discriminación, formal o de facto, que atente contra la dignidad humana o tenga por objeto o resultado la negación, exclusión, distinción, menoscabo, impedimento o restricción de los derechos de las personas, grupos y comunidades, motivada por origen étnico o nacional, apariencia física, color de piel, lengua, género, edad, discapacidades, condición social, situación migratoria, condiciones de salud, embarazo, religión, opiniones, preferencia sexual, orientación sexual, identidad de género, expresión de género, características sexuales, estado civil o cualquier otra. También se considerará discriminación la misoginia, cualquier

\footnotetext{
31 MALARET GARCÍA, Elisenda (2006). "Municipios, democracia cosmopolita y cooperación al desarrollo descentralizada" en Revista de estudios de la administración local y autonómica, núm. 300-301, págs. 73-96. Fecha consulta 14-09-2020. URL: https://revistasonline.inap. es/index.php/REALA/issue/view/603
} 
manifestación de xenofobia, segregación racial, antisemitismo, islamofobia, así como la discriminación racial y otras formas conexas de intolerancia. La negación de ajustes razonables, proporcionales y objetivos, se considerará igualmente discriminación.

Tiene proyección respecto a las familias (art. 6), el acceso a la función pública (art. 7), la ciencia (art. 8), la solidaridad (art. 9), el trabajo (art. 10) y los grupos y personas vulnerables (art. 11). Específicamente se cita en relación con las mujeres, el colectivo LGBTTTI (lesbianas, gays, bisexuales, transgénero, travesti, transexuales e intersexuales) y las minorías religiosas.

La igualdad es por otra parte una condición para el ejercicio del derecho a la movilidad y al disfrute del tiempo libre (art. 13). En materia de movilidad se establece una jerarquía que otorga prioridad a los peatones y conductores de vehículos no motorizados, fomentando una cultura de movilidad sustentable. La previsión es sumamente necesaria, dado que en la Ciudad de México y su zona metropolitana los problemas de transporte son particularmente graves (Lozano, 2017, págs. 67-73) (22 $^{32}$ De esto último se ocupa el artículo 19, donde se dispone que las autoridades deberán impulsar gradualmente un desarrollo incluyente, funcional y eficiente para los habitantes de la Ciudad de México a través de la coordinación con la Federación, los Estados y Municipios conurbados de la Zona Metropolitana del Valle de México y la Región Centro del país, coherente con el Sistema de Planeación Nacional y el de la Ciudad de México. Se identifican como áreas de interés metropolitano la planeación democrática del desarrollo y la prestación de servicios públicos de impacto regional y metropolitano, y las materias de asentamientos humanos, gestión ambiental, movilidad, transporte, agua, saneamiento, gestión de residuos, seguridad ciudadana y demás facultades concurrentes. En desarrollo de todo

32 LOZANO Calvo (2017). "Infraestructura y servicios de transporte", en COSSIO DÍAZ, J. R. y ALCOCER MARTíNEZ DE CASTRO, S. M. (coord.), Infraestructura y Derecho. El caso de la Constitución Política de la Ciudad de México, págs. 59-75. Tirant lo Blanch, Ciudad de México. 
ello se aprobaría la Ley del sistema de planeación del desarrollo de la Ciudad de México, publicada en la Gaceta Oficial el 20 de diciembre de 2019. En ella se abordan cuestiones de movilidad, seguridad y desarrollo urbano.

Respecto al tiempo libre, se dispone que toda persona tiene derecho a tener tiempo para la convivencia, el esparcimiento, el cuidado personal, el descanso, el disfrute del ocio y a una duración razonable de sus jornadas de trabajo. En atención al principio de igualdad sustantiva, las autoridades impulsarán políticas sociales, económicas y territoriales que liberen tiempo y permitan a las personas alcanzar el bienestar.

\subsection{Sobre derecho a la vivienda, medioambiente urbano e igualdad}

El derecho a la vivienda se integra dentro de la concepción de la ciudad solidaria (art. 9). Se dispone así que toda persona tiene derecho a una vivienda adecuada para sí y su familia, adaptada a sus necesidades. Igualmente se prescribe que las autoridades tomarán medidas para que las viviendas reúnan condiciones de accesibilidad, asequibilidad, habitabilidad, adaptación cultural, tamaño suficiente, diseño y ubicación seguros que cuenten con infraestructura y servicios básicos de agua potable, saneamiento, energía y servicios de protección civil. Se dispone que se impulsarán planes accesibles de financiamiento, medidas para asegurar gastos soportables y la seguridad jurídica en la tenencia de la vivienda, y que se adoptarán medidas, de conformidad con la ley, contra el desalojo arbitrario e ilegal de los ocupantes de la vivienda.

La vivienda vuelve a aparecer reforzada en el marco de la ciudad incluyente (art. 11), en particular respecto a los derechos de las personas jóvenes, y es objeto de una regulación detallada en sede de ordenación del territorio (art. 16). Allí se dispone que la vivienda es un componente esencial del espacio urbano, del ordenamiento territorial, de la vida comunitaria y del bienestar de las personas y las familias, y que la Constitución reconoce la producción social y privada de vivienda. 


\subsection{En materia de educación no segregada}

Si bien este concreto aspecto no se menciona expresamente, la educación integral e inclusiva se impulsa por la Ciudad de México para la construcción del futuro (art. 1.6). Se configura un derecho a la educación en sexualidad y servicios de salud integrales, con información completa, científica, no estereotipada, diversa y laica (art. 6). La Ciudad de México asume la educación como un deber primordial y un bien público indispensable para la realización plena de sus habitantes, así como un proceso colectivo que es corresponsabilidad de las autoridades de los distintos órdenes de gobierno en el ámbito de sus facultades, el personal docente, las familias y los sectores de la sociedad (art. 8).

\subsection{Sobre libertad religiosa}

El artículo 6 recoge el derecho a la libertad de pensamiento, conciencia, y religión. Este derecho implica la libertad de tenerla o no, así como de conservarla o cambiarla. Igualmente se dispone que toda persona tiene derecho a actuar de acuerdo a sus convicciones éticas. El artículo 11 reconoce los derechos a una vida libre de violencia y discriminación religiosa, así como a expresar sus convicciones en lo privado y en lo público, en los términos de la ley. No obstante, se reserva un espacio laico para las instituciones públicas y así no podrán acceder a la condición de diputados, alcaldes o jefes de Gobierno los ministros de culto (art. 29, 32, 53).

\subsection{Respecto a la seguridad urbana}

La seguridad urbana y ciudadana es objeto específico del artículo 14 de la Constitución de la Ciudad de México. La primera supone el derecho a vivir en un entorno seguro, a la protección civil, a la atención en caso de que ocurran fenómenos de carácter natural o antropogénico, así como en caso de accidentes por fallas en la infraestructura de la ciudad. La segunda 
conlleva el derecho a la convivencia pacífica y solidaria, y a vivir libre de amenazas generadas por el ejercicio de las violencias y los delitos.

Más allá de esto la seguridad se menciona también respecto a la alimentación y la atención sanitaria (art. 9); es jurídica en clave de derecho al mantenimiento de la vivienda y mercados públicos (art. 10); y se decanta también como un valor en la atención a personas mayores, en situación de calle y privadas de su libertad (art. 11). En el marco de la ciudad habitable, la seguridad es una característica esencial del derecho al espacio público y la movilidad (art. 13).

\subsection{En relación con el buen gobierno y la buena administración}

Buen gobierno y buena administración es el encabezamiento del título sexto (art. 60-67) con previsiones sobre probidad en la función pública, lucha contra la corrupción, fiscalización y régimen de responsabilidades que han merecido bastantes críticas (Sandoval Ballesteros, 2018) . $^{33}$.

La adjetivación es aquí también profusa respecto al gobierno, que resulta ser abierto, integral, honesto, transparente, profesional, eficaz, eficiente, austero, incluyente, y resiliente. Y debe procurar el interés público y combatir la corrupción. Teniendo en cuenta las carencias históricas de la representación democrática en la capital federal a las que ya se ha hecho referencia más arriba, sorprende que la participación no se subraye más.

Existen, no obstante, algunos mecanismos al respecto, diseminados eso sí a lo largo de todo el texto constitucional. Se ha dispuesto así una "silla ciudadana" en las Alcaldías (art. 56) que será ocupada por las o los ciudadanos que así lo soliciten cuando

33 SANDOVAL BALLESTEROS, Irma (2018). "Análisis crítico del título sexto sobre combate a la corrupción y buen gobierno de la constitución política de la ciudad de México", en Boletín Mexicano de Derecho Comparado, vol. 51, núm. 152, págs. 869-912. Fecha consulta 14-09-2020. URL: http://www.scielo.org.mx/scielo.php?pid=S0041-86332018000200869\&script=sci_arttext. DOI: https://doi.org/10.22201/iij.24484873e.2018.152.12929. 
en las sesiones se traten temas específicos de su interés, a fin de que aporten elementos que enriquezcan el debate, con voz pero sin voto. Igualmente se ha creado un Consejo Económico, Social y Ambiental de la Ciudad de México, órgano de diálogo social y concertación pública que se integra por representantes de organizaciones de la sociedad civil, empresariales, de trabajadores y de profesionales, instituciones académicas, así como de las alcaldías y colaborará con el gobierno local, las Alcaldías y el Cabildo en la promoción del desarrollo social incluyente, el cumplimiento de los derechos, el fomento del crecimiento económico sustentable en la viabilidad y equilibrio fiscal de la Ciudad y el empleo, y la justa distribución del ingreso (art. 17).

De manera no sorprendente, uno de los primeros desarrollos constitucionales ha sido, en el verano de 2019, la aprobación de una Ley de participación ciudadana para la Ciudad ${ }^{34}$. La norma está construida sobre una democracia tripartita: directa, participativa y representativa.

Volviendo al texto constitucional, el gobierno abierto se define de manera "sistémica" y así se prevé que los entes públicos deberán informar a través de una plataforma de accesibilidad universal, de datos abiertos y apoyada en nuevas tecnologías que garanticen de forma completa y actualizada la transparencia, la rendición de cuentas y el acceso a la información. Asimismo, se deberán generar acciones y políticas públicas orientadas a la apertura gubernamental a fin de contribuir a la solución de los problemas públicos a través de instrumentos ciudadanos participativos, efectivos y transversales. La ley establecerá los mecanismos para su cumplimiento.

La Constitución en este punto no sólo consagra el derecho a la buena administración, sino que también establece un principio de garantía de su debido ejercicio en la función pública. Se señala así que será garantizado a través de las vías judiciales y administrativas para su exigibilidad y justiciabilidad, eso sí,

34 Publicada en la Gaceta Oficial de la Ciudad de México el 12 de agosto de 2019. 
"en los términos que determine la ley". Por ello, y como se verá con más detalle en el epígrafe siguiente, la consagración constitucional no es suficiente por sí para la implementación de derecho alguno, pues por ejemplo en este caso será imprescindible desarrollar un sistema integrado de gestión pública, de profesionalización de la función pública, de transparencia, acceso a la información y protección de datos personales y un Sistema Local Anticorrupción (Aceves Díaz de León, 2018, pág. 28) ${ }^{35}$.

\section{Discusión}

Dentro de la globalización imperante, es lógico que los distintos actores jurídicos busquen la manera de diferenciarse, subrayar sus compromisos generales y marcar sus prioridades políticas. El lenguaje es a estos efectos una técnica con gran potencial y existen adjetivos muy evocadores que, al unirse al nombre de un determinado agente, generan una fuerte visibilidad con grandes impactos positivos.

Los propios legisladores son conscientes de ello, y así se viene denunciando por ejemplo que, en los últimos tiempos, y sobre todo en algunos contextos, las leyes se están convirtiendo en "relatos publicitarios/plebiscitarios de quienes las promueven" (Taillefait, 2019, pág. 2356) ${ }^{36}$, o en ejercicios de "marketing" (Verpeaux, 220, pág. 205) ${ }^{37}$. La prosa normativa es cada vez menos neutral incluso en países con una sólida tradición de técnica legislativa como Francia, algo que muchas veces lleva a que las leyes contengan previsiones pomposas de

\footnotetext{
35 ACEVES DÍAZ DE LEÓN, Jesús (2018). "El derecho a la buena Administración Pública en la Constitución Política de la Ciudad de México y su aporte a la gobernanza", en López Velarde Campa, J. A. (coord.): La gobernanza en la Ciudad de México. Visiones multidisciplinarias, págs. 17-38. Escuela de Administración Pública, Ciudad de México.

36 TAILLEFAT, Antony (2019). "Déontologie et égalité professionnelle après la Loi Dussopt", en Actualité Juridique. Droit Administratif, núm. 40, págs. 2356-2363.

37 VERPEAUX, Michael (2020). "Une nouvelle loi relative aux collectivités territoriales : Ia proximité ou la décentralisation? ", en Revue française de droit administratif, núm. 2, págs. 205-213.
} 
alcance vacuo, pues no siempre los instrumentos políticos tienen cabida en el derecho positivo por mucho que formalmente se incorporen a él. Si esto es perturbador en el ámbito legal y reglamentario, aún lo es más cuando el fenómeno se produce en una norma constitucional pues, por ejemplo, dudar sobre el verdadero alcance de los adjetivos positivizados acaba conduciendo a cuestionar el valor de la misma Constitución.

Esto es lo que sucede en muchos aspectos de la Constitución Política de la Ciudad de México que hasta aquí se ha venido analizando.

Allí se presenta una ciudad caracterizada, entre otras cosas, como segura, productiva y habitable, lo que para empezar no se sabe si es una mera declaración de estatus (y en tal caso cuál es el parámetro comparativo) o, lo que seguramente es más plausible, una aspiración principial de desarrollo gradual y progresivo. El hecho de tratarse de la primera Constitución de esta entidad federativa, con el contexto histórico y social que aquí se ha presentado, y el haber sido fruto de un ejercicio amplísimo de concertación, da lugar a un texto que resulta muy alejado de la concepción normativa de las Constituciones modernas (García de Enterría, 1979, págs. 293-298) ${ }^{38}$, exagerado e inabarcable incluso en la clave neo-constitucionalista llamada a conectar con el constitucionalismo latinoamericano (Belloso Martín, 2015) ${ }^{39}$.

Esa ciudad, que también es incluyente, solidaria y pluricultural, no se protege con garantías sustantivas concretas, sino por remisión a un catálogo casi interminable de derechos que

\footnotetext{
38 GARCÍA DE ENTERRÍA MARTínEZ-CARANDE, Eduardo (1979). “La constitución como norma jurídica", en Anuario de Derecho Civil, fascículo 2-3, págs. 291-342. Fecha de consulta: 14-09-2020. URL: https://www.boe.es/publicaciones/anuarios_derecho/abrir_pdf. php?id=ANU-C-1979-20029100342

39 BELLOSO MARTín, Nuria (2015). "El neoconstitucionalismo y el "nuevo" constitucionalismo latinoamericano: ¿dos corrientes Ilamadas a entenderse?", en Cuadernos electrónicos de Filosofía del Derecho, núm. 32, págs. 21-53. Fecha de consulta: 14-09-2020. Disponible en: https://ojs.uv.es/index.php/CEFD/article/view/6448/7416
} 
sin embargo no se sabe bien ante quién y cómo podrán hacerse valer. No existe una formulación nítida de principios o reglas, ni parece garantizarse siempre el contenido mínimo esencial de los derechos que permitiría constatar esa realidad adjetiva.

Sirva como ejemplo la configuración del derecho a la salud, que no es plenamente universal, o la ausencia en el texto constitucional de una garantía tan elemental como el saneamiento público de agua en una zona sometida a fortísimas tensiones ambientales y de suministro (Simental Franco, 2014) ${ }^{40}$. Sobre el derecho a la salud, el artículo 9.D.2 limita subjetivamente el acceso al sistema de salud público a los "residentes", al tiempo que el 9.D.3 establece la obligación de las autoridades locales de asegurar "de forma progresiva" la cobertura universal de los servicios e infraestructuras médicos y hospitalarios. Respecto al agua, los artículos 9.F.2 y 9.F.3 consagran la gestión pública y una cobertura universal, pero sin establecer unas elementales obligaciones de calidad (Ruíz de Apodaca Espinosa, 2012) ${ }^{41}$, algo que forma parte intrínseca del mismo derecho subjetivo a su acceso en condiciones de servicio público (Mestre Delgado, 2012) ${ }^{42}$ que, estas sí, se recogen en los mismos incisos del artículo (asequibilidad, continuidad, equidad). Mientras tanto, la suficiencia, seguridad y salubridad quedan sin más enunciadas en términos genéricos en el artículo 9.F.1.

Se trata, en fin, de una declaración programática y engañosa dado que, por ejemplo, no existe un mandato público a la remoción de obstáculos, como en cambio sí refleja, por ejemplo, el artículo 9.2 de la Constitución española de 1978.

\footnotetext{
40 SIMENTAL, Franco (2014). La Ciudad de México, un espacio socio-urbano no sustentable. Una propuesta de sustentabilidad hídrica. Tirant lo Blanch, México.

41 RUIZ DE OPADACA ESPINOSA, Lorenzo (2012). "Las obligaciones de los entes locales en relación con la protección de la calidad de las aguas", en Embid Irujo, A. (dir.), Agua y ciudades, págs. 427-474. Cizur Menor: Civitas-Thomson Reuters.

42 MESTRE DELGAD0, Juan Francisco (2012). “El abastecimiento a poblaciones como servicio público", en Embid Irujo, A. (dir.), Agua y ciudades, págs. 203-231. Cizur Menor: Civitas-Thomson Reuters.
} 
Es cierto que, como también se ha señalado respecto a esta última norma jurídica suprema, el valor de las constituciones tiende cada vez más a desmitificarse, pues no estamos ante un deux ex machina sino ante un instrumento de convivencia, llamado a moverse, desde la hoja de papel, "de lo pintado a lo vivo" (Nieto, 2011, pág. 159) ${ }^{43}$. En efecto, un amplio sector de la doctrina viene subrayando también el valor referencial, cultural e incluso teatral (Häberle, 2003, pág. 84) ${ }^{44}$ de Constituciones que tienen ante todo una función primaria educativa. Son lo que Loewenstein (1976, pág. 2018) ${ }^{45}$ llamaba Constituciones semánticas: un traje que se ha comprado grande, y que ha de colgar en el armario para ser vestido en un futuro próximo. En ese marco creo que es donde debe situarse la declaración de la Ciudad de México como garantista, democrática, educadora, solidaria, productiva, incluyente, habitable, segura, global, hospitalaria, plurilingüe e intercultural.

Así, el reconocimiento constitucional de todos esos fenómenos y derechos en la Ciudad de México seguramente resultara contextualmente necesario, pero desde luego no es suficiente. Estamos, de nuevo, ante un punto de partida y no de llegada. Parece evidente que la Ciudad de México no es hoy una ciudad suficientemente segura, solidaria o incluyente, pero sin duda quiere aspirar a ello. Para lograrlo, de momento se ha acometido la constitucionalización de todos los adjetivos ya vistos; parece que se está retomando el viejo axioma de que una Constitución no sólo expresa formalmente el nuevo orden, sino que contribuye a crearlo y a defenderlo (de Cabo Martín, 1997, pág. 175) ${ }^{46}$. De hecho, siguiendo con el símil de Loewenstein, el traje del

43 NIETO, Alejandro (2011). “Epílogo” en LASALLE, ¿Qué es una Constitución? págs. 155189. Editorial Ariel, Barcelona.

44 HABERLE, Peter (2003). El Estado Constitucional. Editorial UNAM-Instituto de Investigaciones Jurídicas, Ciudad de México.

45 LOEWENSTEIN, Karl (1976). Teoría de la Constitución. Editorial Ariel, Barcelona.

46 DE CABO, Martín (1997). Contra el consenso. Estudios sobre el Estado constitucional y el constitucionalismo del Estado social. UNAM-Instituto de Investigaciones Jurídicas, Ciudad de México. 
armario admite que se saquen las costuras, pero nunca que se estreche, pues en los últimos artículos de la Constitución se dispone específicamente que, en materia de derechos y libertades reconocidos en la Ciudad de México, la Constitución y las leyes que de ella emanen, podrán reformarse sólo para ampliar, proteger y garantizar los derechos de las personas, nunca en su menoscabo (art. 70).

No obstante, si no se trabaja en el desarrollo efectivo del contenido de los múltiples adjetivos, los habitantes de la Ciudad de México pensarán haber vuelto en cierta manera a los tiempos del "obedézcase, pero no se cumpla", y el texto constitucional quedará en un mero ejercicio estilístico de publicidad. 